\title{
Emirati Parents' Attitudes toward the Military and National Service in the United Arab Emirates
}

\author{
Hwee Ling Lim ${ }^{1 *}$, Abdelaziz Khalid Almaeeni ${ }^{2}$, Abdalla Khalid Almaeeni ${ }^{3}$ and Ahmed Alzaabi ${ }^{4}$ \\ ${ }^{1,4}$ Khalifa University \\ Abu Dhabi, United Arab Emirates \\ ${ }^{2,3}$ ADNOC Onshore \\ Abu Dhabi, United Arab Emirates \\ ${ }^{*}$ Corresponding author's email: lim.ling [AT] ku.ac.ae
}

\begin{abstract}
Compulsory national service for male citizens presents the United Arab Emirates (UAE) Armed Forces with an opportunity to recruit future military officers. Research showed that parental attitudes towards the military, manifested through their communication with youths, are likely to influence youths' decision on a military career. Hence this study examined the attitudes of Emirati parents on the UAE military and national service; particularly parental perceptions of the military work environment; support of a military career for their children; and concerns about national service. Surveys, individual and focus group interviews were conducted with 59 Emirati parents. It found that most participants held the positive view that the military work environment helps attainment of professional goals but were uncertain about personal goals and workplace conditions. Also, more participants were supportive of a military career for sons than daughters. It also identified the basis for parental confidence about enlistment as patriotism and development of positive character traits but main concerns were the exposure to harsh training conditions and threat to life during enlistment. Recommendations were provided for better engagement by the UAE military with Emirati parents and the community.
\end{abstract}

Keywords_- Emirati parents, military career, military work environment, UAE national service

\section{INTRODUCTION}

The United Arab Emirates (UAE) introduced compulsory national service in 2014 for male citizens which was prompted by changing political, economic and social circumstances in the country. Regional conflicts led the UAE to realize the need for a strong defense force. To reduce Emirati youths' sense of entitlement and increase local workforce competitiveness, national service would instill discipline, work ethic and other core competencies needed in work and life. Moreover, with a high youth obesity rate, the rigorous in-service training regime that requires recruits to meet military fitness and body weight standards would improve physical fitness and reduce health problems. National service presents the UAE Armed Forces with an opportunity to recruit future military officers. Research showed that parental attitudes towards the military, manifested through their communication with youths, are likely to influence youths' decision on a military career. Hence, this qualitative study examined Emirati parents' perceptions of the military work environment; support of a military career for their children; and their concerns about national service enlistment. The findings could be used by the UAE Armed Forces to refine the program and engage more effectively with Emirati parents and the community for the long-term sustainability of the program.

\section{LITERATURE REVIEW}

Compulsory national service in the UAE was implemented in 2014 for male Emiratis (18 to 30 years old) while it is optional for females. Permanent exemptions are available for those who are the only sons of mothers or medically unfit. Since 2014, the service has undergone several changes. The duration of service increased from nine months in 2014 to 16 months from 2018 [1]. Temporary exemption for youths (below 29 years old) who wish to defer enlistment for enrollment in university ended in 2020 when the National and Reserve Service Authority (NRSA) announced that male Emirati high school graduates with grades of $90 \%$ or higher who plan to enroll for university studies must first complete a four-month basic training course [2]. The service period is typically used by recruiters to identify high-quality individuals to undergo leadership training towards military careers as officers and reduce the military's reliance on foreign personnel. Hence, examining the Emirati parents' attitudes toward the UAE military and national service is a step towards understanding their influence on their children's choice of a military career. 


\subsection{Parental views of the military environment and career}

Research in the United States (US) showed that parents strongly influence their children's career choices. The Parental Model of Enlistment Decision-making developed by Nieva et al. [3] suggests that parents' perceptions of the benefits emphasized by the US Army, that are actually offered to recruits (sons), affect parental attitudes towards their sons' choice of a military career. Parental attitudes are manifested through their communication with youths that is likely to influence youth decision on a military career. This model was supported by later research that found parental attitudes towards the US military perceived by American youths predict the latter's choice of a military career regardless of youths' self-reported enlistment intention [4]. Other research also found that parental intention to recommend a military career and frequency of communication on that issue were positively related to youth propensity to join the military [5].

From 1975 to 1999, the US Department of Defense commissioned The Youth Attitude Tracking Study to examine youth enlistment trends in an all-volunteer army context. It examined American parents' views of the US military service and support of their children's choice of a military career [6-7]. Focus groups were conducted with parents, who were not military staff and had sons eligible for service. Regarding knowledge of enlistment benefits, it found that parents were aware of in-service educational benefits for recruits but uncertain of the actual details. Also, most fathers held positive views of the military service, particularly as a good experience for their sons. However, mothers were mostly negative towards military service due to fears of war and re-introduction of conscription Most parents thought the military environment would help youths achieve personal and professional goals (develop discipline, maturity, make informed career decisions) but believed racism and gender discrimination were present in the military workplace. Regarding parental support of a military career, parents would leave the military career decision to their sons and be supportive of the decision.

In the context of conscription, the national service period is typically used by military recruiters to identify highquality individuals to undergo leadership training and transition into careers as commissioned officers post-national service. A UAE study examined Emirati parents' influence on their children's choice of a military career four months after the service law was introduced in 2014 [8]. Based on survey data from 40 participants, it found that parents held very positive perceptions of benefits present in the military work environment particularly the ability of recruits to obtain recourse for unfair treatment at work and attain professional goals of career development, career advancement and further education. Also, most parents were more supportive of sons pursuing a military career post-national service than daughters taking up a military career. Since parental perceptions (positive or negative) of the military, when communicated to their children, are likely to influence the latter's choice of a military career, the findings suggest military recruiters should consider the role of parents in influencing children's career choices.

\subsection{Parental concerns about national service}

National service enlistment presents challenges to youths that include the physical demands of field and fitness training. Youths also face psychological challenges such as regimentation; loss of identity with the inculcation of military culture; separation from family and friends; and exposure to undesirable habits [9-10]. A one-year study examined Singapore male national servicemen who faced difficulties adjusting to military life due to psychological factors. It found that out of 246 new referrals to the Psychological Medical Branch of the Singapore Armed Forces, $70.1 \%$ of the cases reported adjustment to military life as the main stressor followed by problems with their peers (10.4\%) and superiors (3.9\%). Most cases completed their service successfully but $7.8 \%$ of cases were discharged for psychotic illness. The authors concluded that recruit attrition from adjustment problems constituted a manpower loss for the armed forces [11].

Research on Emirati parents' views about youth enlistment in national service is limited. Media reports largely framed parents' views through a positive patriotic lens of nation-building and strengthening of Islamic religion and traditions [12]. A recent thesis examined the effect of the UAE national service on students' academic performance in higher education and future career development. It sampled Emirati undergraduates who have completed national service, their parents and teachers. Statistical findings presented parental perceptions of pre/post service changes in their children's levels of discipline, commitment to academic studies, and ability to make informed decisions [13]. In contrast, [8] examined Emirati parents' concerns about youth enlistment in national service. Based on survey data gathered in 2014, it found that most parent participants had no concerns about their sons' enlistment due to the reasons that service experience is beneficial at personal (develop confidence, discipline, time management skills) and national levels (strengthen patriotism). However, areas of concerns raised by other parents included Difficulty in adapting to military lifestyle; Negative impact on education plan; Separation from family; Development of bad habits; Harsh training conditions. In comparison to the literature reviewed, this paper reported more recent parental data gathered in 2019 that could enhance engagement between the UAE Armed Forces and Emirati parents. 


\section{METHODOLOGY}

\subsection{Qualitative research framework of study}

In this study, the term methodology refers to the plan of action showing how answers to the research aims would be obtained while methods refer to instruments or techniques for data collection or analysis. Research methodologies are usually classified as quantitative or qualitative and this study adopted a qualitative research methodology. In this approach, it is held that knowledge discovered from participant self-reported views towards the military and national service is based on interpretation in a specific time/context and not claimed to be generalizable to wider populations. However, the findings may be extrapolated to similar conditions and "extrapolations are logical, thoughtful, case derived, and problem-oriented rather than statistical and probabilistic" [14, p.584].

\subsection{Sampling strategy, instruments and measures}

In qualitative research, the human focus of inquiry includes the participants and the researcher. The position of the researcher is significant in the methodological design for determining the intensity of participants' voices in the form of 'thick' descriptions [15]. In this study, the main researcher is an outsider (an UAE expatriate) without access to the Emirati community or its language (Arabic). Hence, three Emirati research assistants were recruited to provide insider access to the local community and its language. As insiders, they were more easily accepted by the participants who were then more willing to share their views on government policies (the military; national service) which could be construed by some as politically sensitive areas. Moreover, the higher levels of trust and openness that come with acceptance added greater depth to the data [16].

A purposive sampling strategy was used to identify parent participants with specific characteristics: UAE citizens; aged 18 years and above in 2018/19; have at least one child who is likely to undergo national service. Snowball sampling was used as it was difficult to find potential participants with the target characteristics [17]. Hence, initial participants were asked to recommend potential participants among their familial and social networks. The total sample was 59: 30 participants completed surveys; 14 participants completed individual interviews and 15 participants completed focus group interviews (3 focus groups). The findings were based on the survey and interview datasets.

Besides insider access to the Emirati community, the research assistants also provided native insights on observed phenomena particularly during transcription and translation of the interview data. As local insights provided may be colored by 'impression management' [18] when insiders tell the researcher what s/he wants to hear, lie or hide information in order to protect themselves and their privacy, this study used multiple data collection methods (survey, individual and focus group interviews) to corroborate insights offered by the research assistants.

Three questionnaires (for survey, individual and focus group interviews) were developed with slight variations of questions. Each questionnaire had the same set of closed questions on demographics and the constructs examined. However, more open-ended questions were included in the interview/focus group questionnaires for eliciting elaborations on participants' choices in the closed questions. This study examined Emirati parents' perceptions of the military work environment; support of a military career for their children; and their concerns about national service. Table 1 lists the main constructs, their definitions and measures used in this study.

Table 1: Constructs and measures

\begin{tabular}{ll}
\hline Constructs & Definitions and measures \\
\hline $\begin{array}{l}\text { Military work } \\
\text { environment }\end{array}$ & $\begin{array}{l}\text { It refers to the extent to which personal and professional goals can be attained from working } \\
\text { in the military. It is measured as perceptions to which military personnel can develop their } \\
\text { careers, have their opinions heard, and be treated fairly at work. }\end{array}$ \\
\hline $\begin{array}{l}\text { Support of } \\
\text { military career }\end{array}$ & $\begin{array}{l}\text { It refers to encouragement given to pursue a military career. It is measured as degree of } \\
\text { parental support given to sons and daughters to pursue a military career. }\end{array}$ \\
\hline
\end{tabular}

\subsection{Validity and ethical issues}

In this qualitative study, the issue of external validity, as generalizability of findings, is irrelevant but internal validity is relevant, in terms of construct validity of instruments as the appropriateness of the questions for eliciting the required information. Construct validity was addressed at the piloting stage which found a) a general difficulty in understanding the questionnaires' instructions and questions worded in English and b) a need to probe brief/superficial responses in interviews. Hence, the final questionnaires were printed in English and Arabic; and interview protocols were amended to offer participants the option to have interviews conducted in either language. These changes ensured participants had access to the language they were most comfortable. Also, probing questions were added to the interview protocol for the 
last open-ended question on parental concerns about enlistment. Other measures to ensure validity included training research assistants in survey and interview protocols; and 'member checking' during transcription/translation stages to clarify the context and meaning of responses with the assistants who conducted the interviews.

In this study, the main ethical considerations were participant protection, confidentiality, and informed consent. Data collection started in June 2018 till December 2019. Institutional Review Board approval for the study protocol was granted in May 2018 and valid till April 2020. This research did not place participants in physical danger. The questions were not likely to upset or cause harm to participants since they are not based on actual experiences with national service. Confidentiality of identity was ensured by not gathering real names of participants, using codes to replace actual participant names in data processing and publications. All participants read, understood and signed a consent form (available in English and Arabic) that included the project aims, assurance of confidentiality, consent to voluntary participation and audio recording of interviews, and the right to withdraw from participation anytime without penalty.

\subsection{Data analysis}

Quantitative data from closed questions were collated and subjected to simple statistical analysis. Individual and focus group interviews were audio-recorded (with consent) and transcription carried out based on the audio files using InqScribe software [19]. Since participants could respond in English or Arabic to the open-ended questions, the qualitative responses in Arabic were translated to English during transcription. The qualitative data was subjected to thematic analysis which is an interpretive process involving identification of common patterns or ideas in the data based on an understanding of the conversational content and context. A bottom-up approach was used to sort responses into broad themes that emerged from the data. Then sub-themes were developed to refine the main themes. In the coding scheme, frequency of theme occurrence was assumed to indicate importance of the idea. Reliability of coding between coders was checked before coding the complete datasets. Finally, the meanings underlying the themes were interpreted based on the research aims. The quantitative results are presented as descriptive statistics, graphical representations (tables, figures), and qualitative results are presented as themes which are illustrated by quotes from the transcripts.

\section{RESULTS AND DISCUSSION}

The 59 participants were Emirati parents with at least one child (55.9\% mothers); $33.3 \%$ had children aged $18-30$ years who (if sons) would be eligible to serve, are serving or had completed national service in 2019 (Table 2). Most participants were 34 to 54 years old $(72.9 \%)$, employed $(67.2 \%)$, with a university degree $(78 \%)$, more than 8 years' work experience $(74.4 \%)$, and a monthly income below US\$7,902 (53.5\%).

Table 2: Participant profile

\begin{tabular}{|c|c|c|}
\hline Demographics & & Parent Participants \\
\hline Nationality & UAE national & $100 \%$ \\
\hline \multirow[t]{2}{*}{ Gender } & Male & $44.1 \%$ \\
\hline & Female & $55.9 \%$ \\
\hline Age range & $22-33$ yrs & $22.1 \%$ \\
\hline \multirow[t]{3}{*}{ (in 2018/19) } & $34-44$ yrs & $42.4 \%$ \\
\hline & $45-54$ yrs & $30.5 \%$ \\
\hline & $55 \mathrm{yrs}$ and above & $05.0 \%$ \\
\hline Marital status & Married & $93.1 \%$ \\
\hline \multirow[t]{2}{*}{ Children } & More than 2 children & $83.0 \%$ \\
\hline & Children aged $18-30$ years* & $33.3 \%$ \\
\hline \multirow[t]{3}{*}{ Employment } & Employed & $67.2 \%$ \\
\hline & Unemployed & $10.3 \%$ \\
\hline & Never worked & $22.4 \%$ \\
\hline \multirow[t]{3}{*}{ Academic level } & Secondary school certificate & $13.6 \%$ \\
\hline & Bachelor's degree & $62.7 \%$ \\
\hline & Master's degree/PhD & $15.3 \%$ \\
\hline \multirow[t]{2}{*}{ Work experience } & $5-6$ yrs & $10.3 \%$ \\
\hline & $8 \mathrm{yrs}$ and above & $74.4 \%$ \\
\hline AV monthly income* & Below US $\$ 7,902$ & $53.5 \%$ \\
\hline
\end{tabular}

* Eligible for draft; **US\$1 = 3.67AED (Oct 2021) 


\subsection{Parental perceptions of the military work environment}

To measure parents' views of the military work environment, participants indicated agreement with a set of statements on the military workplace. The statements were adapted from a study on American high school seniors' view of the military as an occupation and a workplace [20]. The results showed that most participants held a positive view that the military work environment would benefit recruits through attainment of professional goals: further education, career development and career advancement (Table 3) which was consistent with literature findings [7-8]. The results also highlighted aspects where participants were less certain about. Participants were mainly uncertain (Not Sure / Don't Know) about the extent of influence recruits could exert at the workplace (get their ideas heard) (20\%). Participants were also uncertain about the workplace conditions: whether recruits could obtain recourse for unfair treatment by a superior officer and the presence of gender discrimination (14\% each). They were also less certain whether the military work environment supports achievement of personal goals i.e. whether military jobs would be meaningful and rewarding (personally fulfilling jobs) (12\%).

Table 3: Parental perceptions of military work environment (Ranked*)

\begin{tabular}{|c|c|c|}
\hline $\begin{array}{l}\text { Q. To what extent do you agree with the following statements about the military } \\
\text { work environment? People working in the military ... }\end{array}$ & SA/A* & $\begin{array}{c}\text { Not Sure / } \\
\text { Don't Know }\end{array}$ \\
\hline can advance to more responsible positions & $92 \%$ & $2 \%$ \\
\hline can develop their careers & $90 \%$ & $3 \%$ \\
\hline can get more education & $83 \%$ & $7 \%$ \\
\hline can get things changed if treated unjustly by a superior & $78 \%$ & $14 \%$ \\
\hline have personally fulfilling jobs & $64 \%$ & $12 \%$ \\
\hline do not discriminate against women & $63 \%$ & $14 \%$ \\
\hline can get their ideas heard & $54 \%$ & $20 \%$ \\
\hline
\end{tabular}

*Combined responses for Strongly Agree (SA) and Agree (A) points of scale.

\subsection{Parental support of a military career}

To measure parental support of a military career, participants indicated their level of support towards their children (sons and daughters) pursuing a military career. It found that more parents were supportive of a military career postnational service for sons $(79.8 \%)$ than for daughters to pursue a military career $(44.1 \%)$ (Figure 1). Compared to the literature [8], the level of parental support for sons pursuing a military career post-national service was similar (77.5\% in $2014 ; 79.8 \%$ in 2019). However, support for daughters increased from $20 \%$ in 2014 to $44.1 \%$ in 2019 . This change could be the effect of slightly different participant demographics in the two studies. The 2019 participants were better educated (university degree: $78 \%$ in 2019; $57.5 \%$ in 2014). Moreover, mothers had greater representation (female 55.9\% in 2019; $25 \%$ in 2014) and the change may reflect the mothers' support of women's choice of less popular career paths.

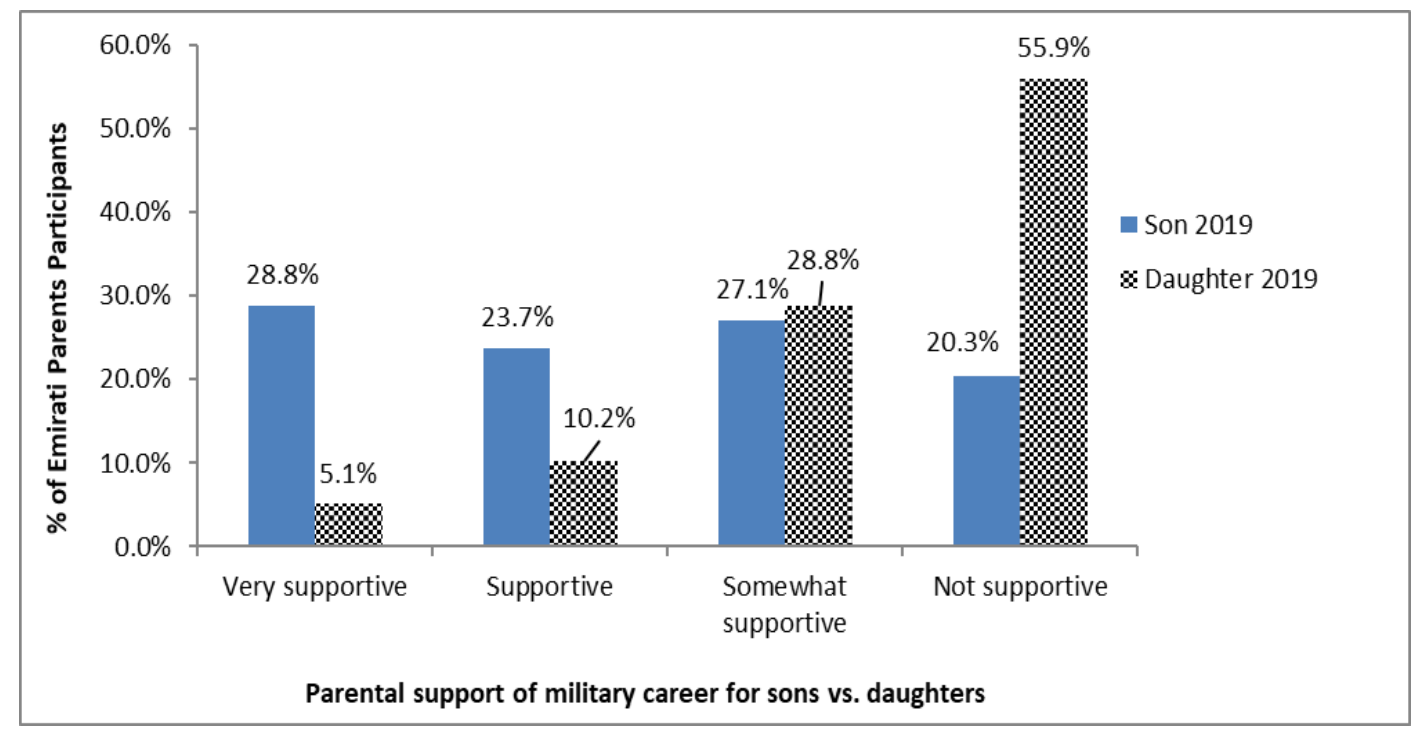

Figure 1: Parental support of a military career for sons and daughters in 2019

While the quantitative data shows trends in parental support of children's career choices, qualitative responses from the interviews provided greater depth of understanding as participants elaborated their decision to (or not) support their children's choice of a military career. The following highlights the main themes (reasons) for parental position on child's choice of military career (Table 4) and quotes from the transcripts (some edited for clarity) are included to represent more accurately participants' voices and meanings. Compared to the literature [7], where few American parents cited 
Patriotism, the main reason for Emirati parents' support of a military career for their children was Patriotism (subthemes: Duty to country; Support national defense). Similar to [7], this study found that most Emirati parents would respect their child's decision to take up a military career and be supportive of the decision.

The common reason for not supporting sons' and daughters' choice of a military career was Negative impact on family life; particularly when personnel on active duty are separated from family due to mission deployments and when aspects of the military culture (regimentation, obedience) extended from the workplace to the home [21]. Reasons specific to not supporting daughters' choice of a military career included cultural/social expectations whereby women are assigned specific roles and responsibilities that are restricted to homemaking as well as concerns over the physical demands of a military job. Reasons specific to not supporting sons' choice of a military career included the availability of other civilian careers and the need to develop entrepreneurship skills rather than accept a stable government job with the military. Interestingly, later in 2021, the media reported that besides military training, recruits would be given lessons in entrepreneurship to turn start-ups into successful commercial and investment projects [22]. This may be considered a step towards broadening the functions of national service by tapping the abilities and skills of Emirati youths to build stronger ties between defense and commercial (non-defense) sectors.

Table 4: Reasons for parental support of military career (Ranked by importance of theme*)

\begin{tabular}{|c|c|}
\hline \multicolumn{2}{|l|}{ Parental reasons for supporting milita } \\
\hline Sons & Daughters \\
\hline $\begin{array}{l}\text { 1. } \text { Patriotism: Duty to country } \\
\text { 2. Patriotism: Support national defense } \\
\text { 3. Respect son's decision to take up military career } \\
\text { 4. Develop positive character traits and new knowledge } \\
\text { 5. Wide range of jobs available in military }\end{array}$ & $\begin{array}{l}\text { 1. Respect daughter's decision to take up military } \\
\text { career } \\
\text { 2. Gender equality } \\
\text { 3. Patriotism: Duty to country }\end{array}$ \\
\hline \multicolumn{2}{|c|}{ Parental reasons for NOT supporting military career choice made by ... } \\
\hline 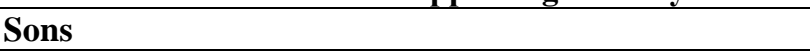 & Daughters \\
\hline $\begin{array}{l}\text { 1. Availability of other civilian careers outside the } \\
\text { military } \\
\text { 2. Need to develop entrepreneurship skills } \\
\text { 3. Negative impact on family life }\end{array}$ & $\begin{array}{l}\text { 1. Cultural and social expectations of appropriate } \\
\text { careers for women } \\
\text { 2. Negative impact on family life } \\
\text { 3. Physical demands in the military }\end{array}$ \\
\hline
\end{tabular}

* Ranking of theme importance based on frequency of theme occurrence.

Parents who supported their son's choice of a military career post-national service provided the following main reasons.

\section{- $\quad$ Patriotism: Duty to country}

The country provides us a lot of benefits since we are young until we leave this earth; from education, from health from housing and from everything. We need to give at least something back to this country. (InterviewG4R2)

The most important matter is to serve his country whether he is a civilian man or a military man. His mission is to serve his country. Since they [sons] have an experience [of national service], they would be perfect in the military field. (InterviewG4R3)

- $\quad$ Patriotism: Support national defense

We need to defend this country and to protect our family, to protect our friends, to protect our rulers. (InterviewG4R2)

The military service .... increases [our] security awareness, grows the national concern, [he would] know how he defends himself, the family and the state. (InterviewG4R14)

- $\quad$ Respect son's decision to take up military career

It depends on [my] son's desire. After enlistment, if he desires to be a military, I would be very supportive (InterviewG4R5)

Parents who were not supportive of their son's choice of a military career post-national service provided the following main reasons.

- $\quad$ Availability of other civilian careers outside the military

My son's talent is that he can [serve] his country with other things not just in the military as he is an engineer. (G4 FG\#2)

- $\quad$ Need to develop entrepreneurship skills

I prefer for him to earn his money rather than serving the country ... I will not encourage him after the national service [to join military as a career]. I will direct him to something where he can become either a man with a handcraft [a work skill], he does something and knows how to do it, or to become like a merchant where he can make his own money .... I like to let my son to know how to earn money rather than getting the money easily. (InterviewG4R1)

- Negative impact on family life

My father was in the military ... to be a part of that was as if you have no family and I wouldn't want that for my son to be honest ... stuff like that would happen at the house it would just like with temper issues ... it was too strict for kids 
like us at the time. He taught ... in a strict manner when it can be taught in any other kind of way but just because he came from that [military] background, we feared him sometimes. (InterviewG4R6)

Parents who supported their daughter's choice of a military career provided the following main reasons.

- Respect daughter's decision to take up military career

If she desires, I will not stop her as she wishes to continue in the army ... She is serving her country in both cases. ... They [are] free to choose. (InterviewG4R4)

- $\quad$ Gender equality

We need to have female resources in the military for a certain type of job in the military. I support the ladies [women] to work for the military. (InterviewG4R2)

I feel that the passing of years has change the stereotypes. Now the girl is not staying at the house all day. Now there is a semi equality between men and women in meaning the woman has to rely on herself in terms of self-defense and all the matters of her life. (G4 FG\#2)

- Patriotism: Duty to country

She can serve her country in this field [the military]. (G4 FG\#2)

Parents who were not supportive their daughter's choice of a military career provided the following main reasons.

- $\quad$ Cultural/social expectations of appropriate careers for women

She [a woman] has another job, which is staying at home and teach her kids to love this country ... to serve this country [this way is] much better than being in the front of the line. [Her duty is] to build right men to serve this country. (InterviewG4R2)

I do not see frankly ... any need for [a military career] for the ladies ... the media, they try to promote that women are serving and they are making the picture [creating an image] that all the women are serving, so I see that there is a bad intention from those media to promote equity, equality between the two sexes, but I see it is more complementary, I know the women, they raise generations with moral, everything and they are more assigned to their houses, to their families at home and the men, he does and go do the earnings for living. But getting both outside the home, who is going to take care of the home? From that perspective, I am against it. It is a religious thing and it is even a culture here. (InterviewG4R1)

- $\quad$ Negative impact on family life

I have known one of my relatives who is working in the police. She is always [sent] away for missions or trainings so she has been absent from her children and the father also is not existing so that you think that the children are lost between them. So, if there is a balance and they can raise their children even if she is in the military, it is alright. If there is no balance, you would destroy your children's life in that way. (InterviewG4R9)

In the military .... they send their people away for abroad missions so they won't with their children. You know that the core of raising [children] is the mother. You can say that the mother's share of raising is about $80 \%$ rather than the father because the father is responsible of expenses and instructions. Unlike the mother, the father is not taking care of his children all the time. (InterviewG4R9)

- $\quad$ Physical demands in the military

A military career will include, you know, discipline, physical work and many other aspects. (InterviewG4R12)

I just afraid of the physical effort [required from] a girl. (InterviewG4R14)

\subsection{Parental concerns about enlistment in national service}

"We are sending them there [to national service] to train them and serve their country but at the same time these are our children." (G4 FG\#2, R3)

The final question in all the questionnaires (survey, individual and focus group interviews) was an open-ended question that asked participants if they had any concerns about their children enlisting for national service. Participants who had concerns were asked to elaborate while those with no concerns were asked to explain their position. Table 5 lists the main reasons for parental concerns and reasons why parents had no concerns about enlistment in national service. The main areas of concern about enlistment were harsh training conditions and threat to life. Participants were afraid that their children may face adjustment problems with the sudden change from a civilian to a military life. They also voiced fears that their children may die or be injured during service. The media had reported several cases of fatalities among recruits since the program's implementation [23-25]. These two predominant themes were consistent with literature findings on parental concerns [8].

Participants in a focus group were particularly candid about the military's lack of communication to parents and recruits on national service program structure which led to a lack of understanding about the goals of the program and its training exercises. Alterman and Balboni [26] reported that the program structure included three phases: Basic military training (BMT); specialized training; and applied training. The BMT phase covers adjusting recruits' attitudes; building social cohesion; physical and military training; and theoretical courses. The second and third phases involve training and 
apprenticeship for specific jobs in a branch of the armed forces or a government ministry. Moreover, based on an an interview with NRSA officials in 2016, the agency improved information access for family and created an information hotline. Although there seems to be an underlying structure to the program, the finding that parents in this study; who were mostly employed and well educated, were not aware of it suggests an area for improvement in NRSA's engagement with the Emirati community.

Table 5: Parental main concern of about enlistment (Ranked by importance of theme*)

\begin{tabular}{|l|l|}
\hline $\begin{array}{l}\text { Reasons for parental concerns about children's } \\
\text { enlistment in National Service }\end{array}$ & $\begin{array}{l}\text { Reasons for parents having NO concerns about children's } \\
\text { enlistment in National Service }\end{array}$ \\
\hline 1. Harsh training conditions & 1 . Develop positive character traits, behavior, and attitudes \\
\hline 2. $\quad$ Threat to life & 2. Patriotism: Duty to country \\
\hline $\begin{array}{l}\text { 3. } \\
\text { Lack of communication to parents/recruits on } \\
\text { national service program structure }\end{array}$ & $3 . \quad$ Patriotism: Support national defense \\
\hline $\begin{array}{l}\text { 4. } \\
\text { trainers of communication between recruits and }\end{array}$ & $4 . \quad$ Confidence in the UAE government and military \\
\hline 5. Develop bad habits, behavior, friends & 5. Positive previous experience in the military \\
\hline 6. Negative impact on family life & 6. Improvements were made in national service program \\
\hline
\end{tabular}

* Ranking of theme importance based on frequency of theme occurrence.

Parents with no concerns about their children's enlistment attributed it to the positive effects of the service: Development of positive character traits, behavior, and attitudes and Patriotism. Patriotism and its sub-themes (Duty to country; Support national defense) were the main reasons for parents' confidence about enlistment reflecting their belief that through national service, their children are building a country that reflects the values held to be important and that the service experience reinforces (among youths) the importance of protecting the country from national security threats. The findings are substantiated by media reports of a 75\% decrease in crimes committed by young Emirati between 2015 to 2017 [27] and personal reflections on the service experience which indicated that recruits developed a stronger sense of patriotism, social cohesion and discipline [28]. The following highlights the main reasons for parental concern (and lack of) about their children's enlistment illustrated with quotes from the data.

Parents who have concerns about their children's enlistment provided the following main reasons.

\section{- $\quad$ Harsh training conditions}

The training and from what I have heard from the former recruits about the training concerns me. (SurveyG4R19)

... because he (the recruit) just had his life change [from civilian to military] so he is not used to it and he just starting to train so they should not pour all the work on them all at once. It should be taught slowly not just strict and hard on them. (G4 FG\#2)

- $\quad$ Threat to life

Yes, I heard a lot about boys who enlisted and got injured or died. As a mother I am scared to let my only son go to national service and face those injuries. (SurveyG4R23)

... because I heard about the boys who died when enlisting in national service due to health issues recruiters overlooked or the excessive amount of workout. (SurveyG4R22)

- $\quad$ Lack of communication to parents and recruits on national service program structure

... there is a methodology to be followed ... setting a methodology is a must. It is not just to [join] military training without knowing his [recruit's] role in this training. It is not right to wake up and stay until night without having any idea about the purpose of doing this ... All he knows that it is a training without knowing the plans. (G4 FG\#4)

It is necessary to set a methodology for a year or a year and half, according to the period, in which the student is aware of his achievements. I do not want my son to enlist while some vulnerabilities already exist. Hence, he would end the national service as a military and system hater. (G4 FG\#4)

Parents who do not have concerns about their children's enlistment provided the following main reasons.

- $\quad$ Develop positive character traits, behavior, and attitudes

National service made many good things [brought benefits], especially for young men. [Unemployment] is reduced, night times are limited, they are a little bit restricted [disciplined] and they have more obligations at home. Previously, if you rebuked your son, he would tell you "Ok ... Ok" and did not listen to you. So, the national service corrected many issues like this. There is now a respect to parents, which was not existed earlier. (InterviewG4R4)

They [male youths] have become more responsible even in the respect of studying ... when they [enter] the university, they are going to study and work hard until graduation. Before enlisting, there are young people, at the beginning of first or second years, hang out and not focused on their studies till the third year when their education level has become lower because of their hanging out. (InterviewG4R9) 


\section{- $\quad$ Patriotism: Duty to country}

I have no concerns on my children, because it is their duty to serve their country. (SurveyG4R16)

[National Service is] an important thing for them to know what their country stands for and to refresh their patriotism toward their country. (InterviewG4R11)

- $\quad$ Patriotism: Support national defense

I have no concerns, because we are all to serve and defend the country. No one will protect the country except its people. (SurveyG4R12)

I have no concerns about my son enlisting for national service, because it gives him the chance to defend his country and family if needed. (SurveyG4R15)

\section{CONCLUSION AND RECOMMENDATIONS}

This study examined the attitudes of Emirati parents on the UAE military and national service; focusing on parental perceptions of the military work environment; support of a military career for their children; and their concerns about national service. It found that most participants held the positive view that the military work environment helps attainment of professional goals but were less certain about the achievement of personal goals and the workplace conditions. Also, most participants were supportive of a military career post-national service for sons but less supportive of daughters pursuing a military career.

When it is assumed that that parental perceptions (positive or negative) of the military work environment affect their attitudes (supportive or unsupportive) towards their children' choice of a military career, three areas of uncertainty found indicate specific gaps in parental knowledge about the military workplace that the UAE Armed Forces could remedy to encourage parents to communicate positively with their children about a military career:

- $\quad$ whether military jobs would be meaningful and rewarding

- whether recruits would have recourse if treated unjustly by a superior officer

- the presence of gender discrimination

When Emirati parents are increasingly educated and participative, they are likely to demand more transparency and accountability from the NRSA since they have entrusted their children to its care. Therefore, understanding and addressing parental concerns regarding their children's enlistment in national service could enable the UAE Armed Forces to gain stronger support from the Emirati community and ensure sustainability of the program. Moreover, parental perception that their children would have a positive national service experience could influence their support of their children's choice of a military career post-national service. This study found that parents were mainly concerned about the exposure to harsh training conditions and threat to life during enlistment. Particularly, parents called for better information dissemination by the NRSA about the program's goals. The study also found the basis for parental confidence about enlistment as Patriotism and Development of positive character traits, behavior, and attitudes.

This study's findings of specific gaps in parental knowledge about the military workplace and concern about a lack of communication from the NRSA on the program structure and goals suggest areas for improving engagement with the Emirati community. It is recommended that a) commanders carry out home visits to build trust and reassure parents of the NRSA's commitment to their children's welfare during service; b) organize Open Houses during which family members could see recruits' training and living conditions during the BMT period; c) award a certificate of completion at the end of service that includes a transcript of all the courses completed (reflecting the program structure); achievements (awards, commendations); competencies and skills acquired during service. Similar to the Certificate of Service (COS) provided by the Ministry of Defense Singapore to full-time national servicemen [29], this certificate would be a record of achievement that recruits could use when seeking employment or university admission.

Finally, the scope of this study is necessarily limited and future research could expand on this work in several aspects. As this study captured parental views towards the military and national service in 2019 and comparison with the literature showed some differences over time, an annual survey could be developed for tracking changes in parental perceptions that would help the NRSA respond in a timely manner to issues found. Also, this paper presented the parental view as a whole and future work could differentiate between views of fathers and mothers on the military and national service.

\section{ACKNOWLEDGMENT}

This work was financially supported by the grant ADEK Award for Research Excellence (AARE) 2017 under Grant No. AARE17-186. The authors acknowledge the Arabic translation assistance provided by Dr. Elrashid Yousif Abbas, Khalifa University, College of Arts \& Sciences, Abu Dhabi, United Arab Emirates.

\section{REFERENCES}

[1] TDRA. (2021, 16 September). Preserving the Emirati national identity. Available: https://u.ae/en/informationand-services/social-affairs/preserving-the-emirati-national-identity

[2] The National. (2020, 14 September). All male Emirati pupils due to graduate this year must enrol in National Service. Available: https://www.thenationalnews.com/uae/government/all-male-emirati-pupils-due-to-graduate-this-yearmust-enrol-in-national-service-1.988292 
[3] V. F. Nieva, M. J. Wilson, D. G. Norris, J. B. Greenlees, and J. Laurence, "Enlistment Intentions and Behaviors: Youth and Parental Models," Human Resources Research Organization, Alexandria, VA, 1997.

[4] P. J. Legree et al., "Military enlistment and family dynamics: Youth and parental perspectives," Military Psychology, vol. 12 , no. 1, pp. 31-49, 2000.

[5] J. L. Gibson, B. K. Griepentrog, and S. M. Marsh, "Parental influence on youth propensity to join the military," Journal of Vocational Behavior, vol. 70, no. 3, pp. 525-541, 2007.

[6] M. Achatz, S. Perry, M. Kudela, and J. D. Lehnus, "Interviews with Parents of 1998 Youth Attitude Tracking Study Respondents," Defense Manpower Data Center, Arlington, VA, 2000.

[7] A. R. Lancaster and J. D. Lehnus, "Declining interest in military service: Qualitative insights," presented at the International Military Testing Association (IMTA) Conference, U.S. Air Force Personnel Center, San Antonio, 1214 November, 1996. Available: https://apps.dtic.mil/sti/citations/ADA363936

[8] [8] H. L. Lim, "Perceptions of Emirati Youths and Parents on Military Career and Work Environment in National Service Context," in International Symposium on Social Sciences and Management (ISSSM), Osaka, Japan, 2018, pp. 222-230: Higher Education Forum.

[9] N. F. Chu, W. Der-Min, M. H. Shen, and Y. S. Lin, "Prevalence of adverse behaviors among young military conscripts in Taiwan," Military Medicine, vol. 171, no. 4, p. 301, 2006.

[10]M. Scharf, O. Mayseless, and I. Kivenson-Baron, "Leaving the parental nest: Adjustment problems, attachment representations, and social support during the transition from high school to military service," Journal of Clinical Child \& Adolescent Psychology, vol. 40, no. 3, pp. 411-423, 2011.

[11]C. S. Cheok, Y. G. Ang, W. M. Chew, and H. Y. Tan, "Adjusting to military life: Servicemen with problems coping and their outcomes," Singapore Medical Journal, vol. 41, no. 5, pp. 218-220, 2000.

[12]A. Al Khoori. (2014, 2 August). Older Emiratis support national service for nation's youth. Available: https://www.thenational.ae/uae/government/older-emiratis-support-national-service-for-nation-s-youth-1.570860

[13]F. Al Hammadi, "Impact of the UAE national service on academic achievement among college students," PhD in Education, Faculty of Education, The British University in Dubai, Dubai, UAE, 2021.

[14] M. Q. Patton, Qualitative Research and Evaluation Methods, 3rd ed. Thousand Oaks, CA: Sage Publications, 2002.

[15]C. Geertz, "The Interpretation of Cultures: Selected Essays," in Thick description: Toward an interpretive theory of culture, C. Geertz, Ed. New York: Basic Books, 1973, pp. 3-30.

[16]S. C. Dwyer and J. L. Buckle, "The space between: On being an insider-outsider in qualitative research," International Journal of Qualitative Methods, vol. 8, no. 1, pp. 54-63, 2009.

[17]F. Ghaljaie, M. Naderifar, and H. Goli, "Snowball sampling: A purposeful method of sampling in qualitative research," Strides in Development of Medical Education, vol. 14, no. 3, pp. 1-4, 2017.

[18] S. Delamont, "Ethnography and participant observation," in Qualitative Research Practice, C. Seale, G. Gobo, J. Gubrium, and D. Silverman, Eds. London: Sage, 2004, pp. 217-229.

[19]Inquirium. (2020, 19 October). InqScribe: Digital media transcription software. Available: https://www.inqscribe.com/

[20] J. G. Bachman, P. Freedman-Doan, and P. M. O'Malley, Youth, Work, and Military Service: Findings from Two Decades of Monitoring the Future National Samples of American Youth. Defense Manpower Data Center, Arlington, VA: Defense Technical Information Center, 2000.

[21]K. A. Speck, "Parenting Styles of Military and Civilian Families: The Impact of Deployment, Mood, and Marital Satisfaction," Doctor of Philosophy, Department of Medical and Clinical Psychology, Uniformed Services University, Bethesda, Maryland, 2012.

[22] The National. (2021, 14 September). UAE national service recruits to get lessons in entrepreneurship. Available: https://www.thenationalnews.com/uae/government/uae-national-service-recruits-to-get-lessons-in-entrepreneurship1.1196937

[23] The National. (2014, 28 September). Sheikh Mohammed offers condolences to family of dead national service recruit. Available: https://www.thenationalnews.com/uae/government/sheikh-mohammed-offers-condolences-tofamily-of-dead-national-service-recruit-1.239590

[24]A. Ahmad. (2015, 2 August). Tributes after UAE army recruit, 17, dies. Available: https://www.thenational.ae/uae/tributes-after-uae-army-recruit-17-dies-1.64440

[25] S. Al-Nowais. (2018, 18 October). UAE National Service recruits screened for heart conditions in drive to save lives. Available: https://www.thenational.ae/uae/uae-national-service-recruits-screened-for-heart-conditions-in-driveto-save-lives-1.712202

[26] J. B. Alterman and M. Balboni, "Citizens in training: Conscription and nation-building in the United Arab Emirates," Center for Strategic and International Studies, Washington, DC, 2017.

[27]S. Al-Nowais. (2017, 30 May). National Service reduces UAE's crime rate. Available: https://www.thenational.ae/uae/national-service-reduces-uae-s-crime-rate-1.54799

[28]T. Al-Subaihi. (2017, 2 August). UAE National Service recruits learn life lessons in discipline, friendship and sacrifice. Available: https://www.thenational.ae/uae/government/uae-national-service-recruits-learn-life-lessons-indiscipline-friendship-and-sacrifice- 1.87587 
Asian Journal of Humanities and Social Studies (ISSN: 2321 - 2799)

Volume 9 - Issue 6, December 2021

[29]MINDEF. (2021, 19 October). Fact Sheet - Enhanced Certificate of Service for Full-time National Servicemen. Available: https://www.mindef.gov.sg/web/portal/mindef/national-service/discover-ns 